Portland State University

PDXScholar

$10-2014$

\title{
Hyperspectral Measurements of Wet, Dry and Saline Soils from the McMurdo Dry Valleys: Soil Moisture Properties from Remote Sensing
}

\author{
Joseph S. Levy \\ Jackson School of Geoscieces \\ Anne Nolin \\ Oregon State University \\ Andrew G. Fountain \\ Portland State University, andrew@pdx.edu \\ James W. Head \\ Brown University
}

Follow this and additional works at: https://pdxscholar.library.pdx.edu/geology_fac

Part of the Environmental Sciences Commons, Geology Commons, and the Glaciology Commons Let us know how access to this document benefits you.

\section{Citation Details}

Levy, J., Nolin, A., Fountain, A., \& Head, J. (2014). Hyperspectral measurements of wet, dry and saline soils from the McMurdo Dry Valleys: soil moisture properties from remote sensing. Antarctic Science, 26(5), 565-572. doi:10.1017/S0954102013000977

This Article is brought to you for free and open access. It has been accepted for inclusion in Geology Faculty Publications and Presentations by an authorized administrator of PDXScholar. Please contact us if we can make this document more accessible: pdxscholar@pdx.edu. 


\title{
Hyperspectral measurements of wet, dry and saline soils from the McMurdo Dry Valleys: soil moisture properties from remote sensing
}

\author{
JOSEPH LEVY ${ }^{1}$, ANNE NOLIN ${ }^{2}$, ANDREW FOUNTAIN $^{3}$ and JAMES HEAD ${ }^{4}$ \\ ${ }^{1}$ University of Texas Institute for Geophysics, Jackson School of Geosciences, Austin, TX 78758, USA \\ ${ }^{2}$ College of Earth, Ocean, and Atmospheric Sciences, Oregon State University, Corvallis, OR 97331, USA \\ ${ }^{3}$ Department of Geology, Portland State University, Portland, OR 97210, USA \\ ${ }^{4}$ Department of Geological Sciences, Brown University, Providence, RI 02912, USA \\ joe.levy@utexas.edu
}

\begin{abstract}
Soil moisture is a spatially heterogeneous quantity in the McMurdo Dry Valleys of Antarctica that exerts a large influence on the biological community and on the thermal state of Dry Valleys permafrost. The goal of this project was to determine whether hyperspectral remote sensing techniques could be used to determine soil moisture conditions in the Dry Valleys. We measured the spectral reflectance factors of wetted soil samples from the Dry Valleys under natural light conditions and related diagnostic spectral features to surface layer soil moisture content. Diagnostic water absorption features in the spectra at $1.4 \mu \mathrm{m}$ and $1.9 \mu \mathrm{m}$ were present in all samples, including samples doped with high concentrations of chloride salts. The depth of the $1.4 \mu \mathrm{m}$ absorption is shown to increase linearly with increasing gravimetric water content. These results suggest that airborne hyperspectral imaging of the Dry Valleys could generate soil moisture maps of this environment over large spatial areas using non-invasive remote-sensing techniques.
\end{abstract}

Received 4 September 2013, accepted 16 December 2013

Key words: active layer, permafrost, spectroscopy, terrestrial environment, water tracks

\section{Introduction}

Soil moisture is a key physical parameter for understanding biological and physical processes in the McMurdo Dry Valleys of southern Victoria Land, Antarctica. Liquid water is the limiting nutrient in the cold polar desert ecosystem of the Dry Valleys $\left(77-78^{\circ} \mathrm{S}\right.$, $161-164^{\circ} \mathrm{E}$ ) (Fig. 1), and its heterogeneous seasonal and spatial distribution in soils is a strong determinant of biological community structure and size (Kennedy 1993, Virginia \& Wall 1999, Levy et al. 2013). Likewise, soil moisture has a strong effect on physical and thermodynamic processes in the Dry Valleys, such as depth of permafrost thaw (Hunt et al. 2007, Ikard et al. 2009, Levy et al. 2012a). In order to understand the impact of changes to the soil moisture state of the Dry Valleys, which could have significant biological and thermodynamic consequences (e.g. permafrost melting) (Bockheim et al. 2007, Gooseff et al. 2013), it is important to determine how much water is present in Dry Valleys soils, and how soil moisture distribution changes through time.

Volumetrically, most melt water moving through the Dry Valleys environment flows only during summer months (December-February), and is derived from glacial melt runoff, which flows overland through stream channels to perennially ice-covered lakes
(McKnight et al. 1999). Meltwater is only delivered to the soil environment by the glaciers-streams-lakes system at stream and lake margins, where hyporheic exchange wicks water into adjacent soils (McKnight et al. 1999) or where glacier runoff directly infiltrates into the seasonally thawed active layer. Outside of glacier runoff zones, spatially distributed sources of shallow groundwater to the active layer include melt from seasonal and perennial snow banks (Barrett et al. 2009, Levy et al. 2011, Gooseff et al. 2013), thawing of ground ice (Lyons et al. 2005, Harris et al. 2007, Levy et al. 2011) and exotic processes, such as direct vapour emplacement and salt deliquescence (Wilson 1979, Levy et al. 2012b).

Typically, soil moisture is determined in the Dry Valleys as a point measurement. Surface or shallow-subsurface sediments are commonly analysed in situ with a soil moisture probe, for example via time domain reflectometry (TDR) or dielectric properties measurements (Barrett et al. 2009, Levy et al. 2012a), or in the laboratory via gravimetric water content (GWC) analysis. While GWC measurements are extremely robust (high precision and high accuracy), they only provide measurements of soil moisture in a small volume of soil (typically $<1$ litre) at one point in time. TDR measurements can provide a timeseries of soil moisture values in the monitored soil volume (typically $<1-2$ litre), but, like other point measurements, only record conditions at the specific locations of the water 


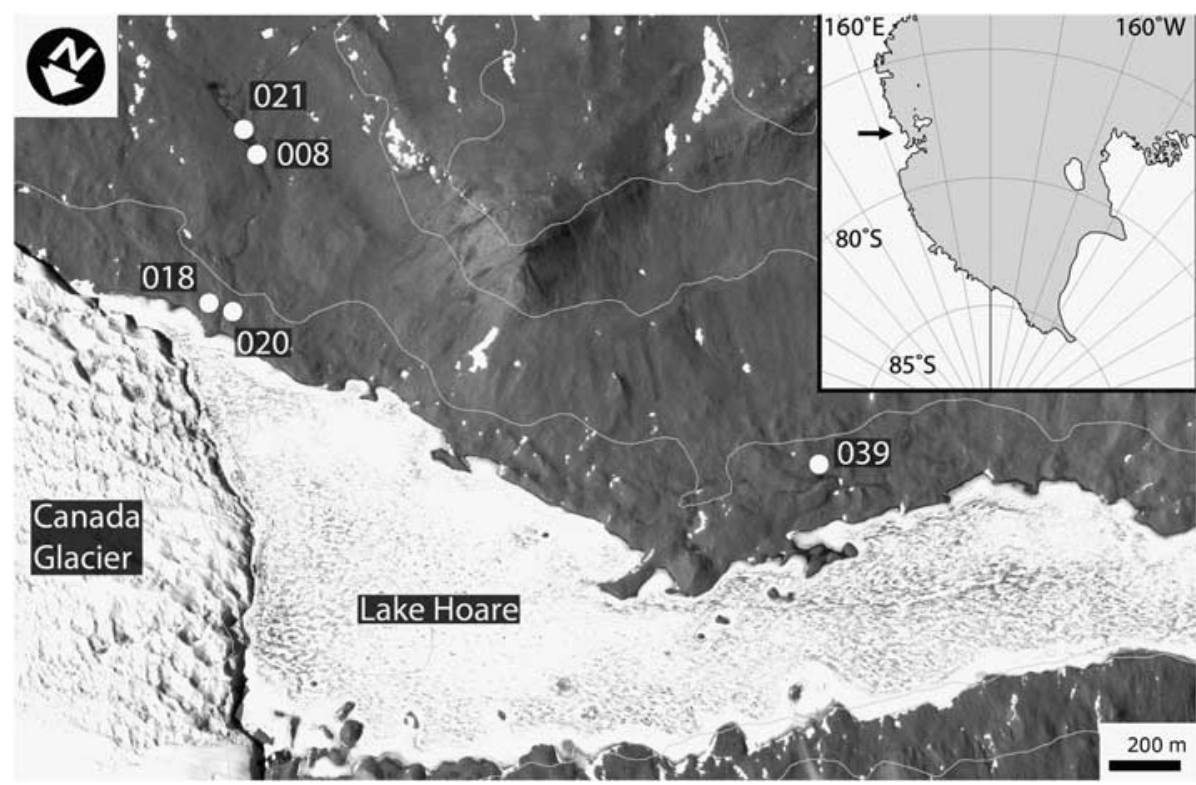

Fig. 1. Sample locations used in this study. Sediments were collected from the Lake Hoare basin in Taylor Valley, McMurdo Dry Valleys. Inset map shows the general location of the Dry Valleys (arrow). Image is a portion of QuickBird image 09FEB01213752. content probe. The TDR or dielectric measurements can determine GWC with intrinsic instrument accuracy of $\pm 0.5-1 \%$ GWC if soil-specific calibration measurements are made to account for high-salinity Dry Valleys soils (Levy et al. 2012a), or $\pm 2 \%$ GWC for uncalibrated sensors.

In contrast to ground-based, contact measurements, several remote-sensing techniques could be applied in the Dry Valleys to measure water content at the soil surface. Remote-sensing measurements of soil moisture have the potential advantages of measuring across wide swaths of the soil environment, while also measuring in a non-invasive manner, reducing the chance of contamination or disturbance of fragile and protected Dry Valleys soil ecosystems (Campbell et al. 1998).
Spaceborne remote-sensing techniques that measure long wavelengths (e.g. thermal infrared or microwave) are very sensitive to soil moisture content and can measure over a large area (sensor footprint), but have the disadvantage of coarse sensor spatial resolution (i.e. pixel size). For example, the Advanced Spaceborne Thermal Emission and Reflection (ASTER) radiometer visible and nearinfrared (NIR) data are collected at $15 \mathrm{~m} \mathrm{pixel}^{-1}$ (Abrams 2000), and the Soil Moisture Active Passive mission microwave measurements are made at $c .0 .4-1 \mathrm{~km} \mathrm{pixel}^{-1}$ (Entekhabi et al. 2008, 2010). These sensors are not able to resolve soil moisture in small features, such as water tracks and wet patches (Levy et al. 2011, 2012b) that are typically a few metres wide at most.

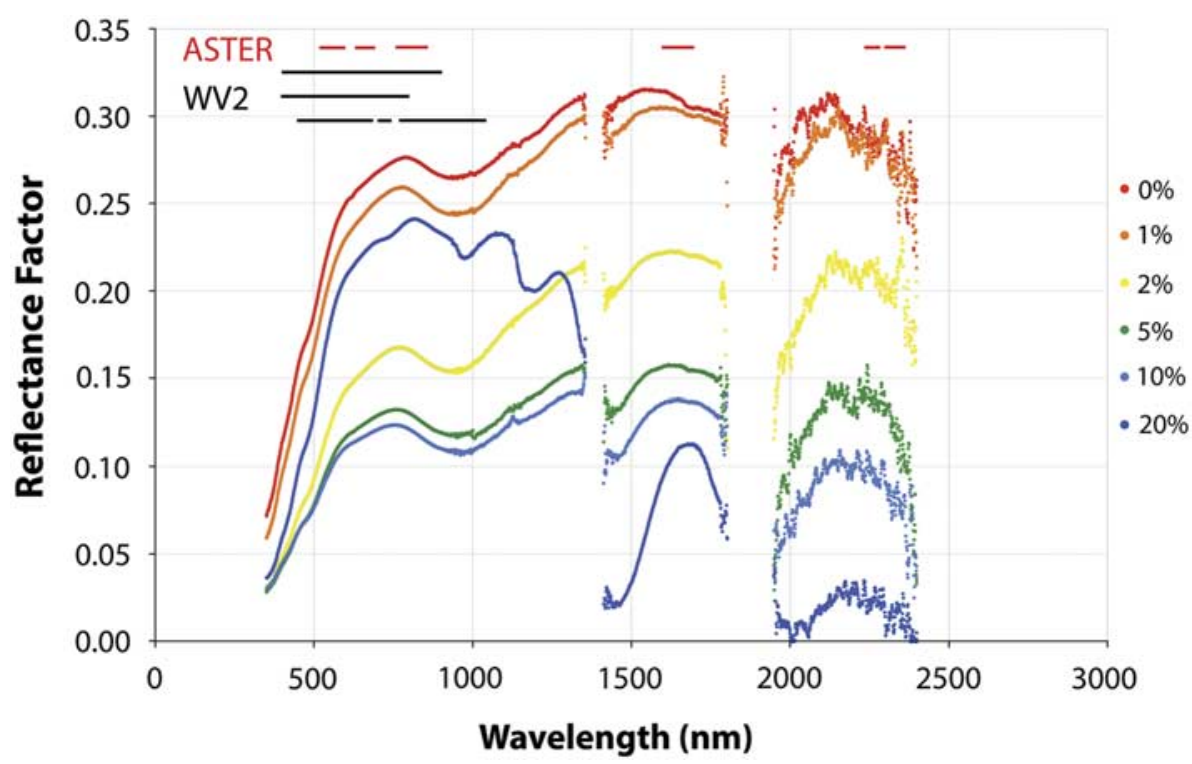

Fig. 2. Example reflectance spectrum (sample 018). Spectra are colourcoded by gravimetric water content (GWC). Bars at the top of the image show the location of existing spacebased multispectral sensor observation wavelengths for ASTER and WorldView-2. Note that the increase in visible and near-infrared (NIR) reflectance at 20\% GWC, and the presence of unusual absorptions in the NIR at these wavelengths is probably due to specular reflection from pooled water. It is not a result of changes to the reflectance properties of the soil minerals themselves at high GWC. 


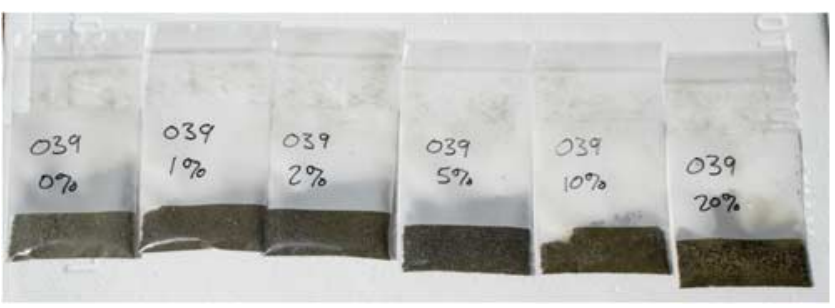

Fig. 3. Sediment samples prepared for analysis. Based on visual inspection alone, it is very difficult to discern differences in soil colour and texture based on water content. Most darkening occurs in the first few weight percent of water. Sample bags are $c .8 \mathrm{~cm}$ wide.

Modern panchromatic satellite sensors, such as IKONOS and WorldView-2 (WV2), have sufficiently fine spatial resolution to detect heterogeneous soil moisture on the scale of metres (typical of the Dry Valleys). As a result, these high-resolution imaging tools can be used to qualitatively assess the distribution of soil moisture in the Dry Valleys, distinguishing light and dark soils (e.g. dry versus wet soils) (Langford et al. unpublished). However, soil darkening due to wetting occurs rapidly as soil moisture increases from $0 \%$ to $c .5 \%$, is strongly dependent on soil type and texture, and can be difficult to distinguish from shadowing in remote sensor datasets. These factors make panchromatic albedo an unreliable measurement of quantitative soil moisture content across wide regions, such as the Dry Valleys (Idso et al. 1975, Graser \& Van Bavel 1982, Bockheim et al. 2007, Gooseff et al. 2013).

Spectroscopic water absorption features in the NIR, particularly absorptions at 1.4 and $1.9 \mu \mathrm{m}$, can be strong determinants of moisture content in soils, with absorption strength (band depth) increasing with increasing moisture content (Clark \& Roush 1984, Chinn 1993, Lobell \& Asner 2002, Finn et al. 2011). However, one hazard of NIR water absorption measurements is that atmospheric water vapour absorbs nearly all photons in the central wavelength of these features (Fig. 2), making it difficult to detect the soil signal. For this reason, most space-based multispectral instruments do not include observation windows in the vicinity of the 1.4 and $1.9 \mu \mathrm{m}$ water absorption features.

Accordingly, the goal of this project was to determine if there are suitable hyperspectral parameters in the vicinity of the 1.4 and $1.9 \mu \mathrm{m}$ water absorption features that could be used by air- or spaceborne sensors to quantitatively determine the soil moisture content of diverse soils in the Dry Valleys. We accomplished this goal by combining laboratory measurements of soil moisture content with spectroscopic measurements of wetted Dry Valleys soils made under natural illumination conditions comparable to those that would be experienced in the field.

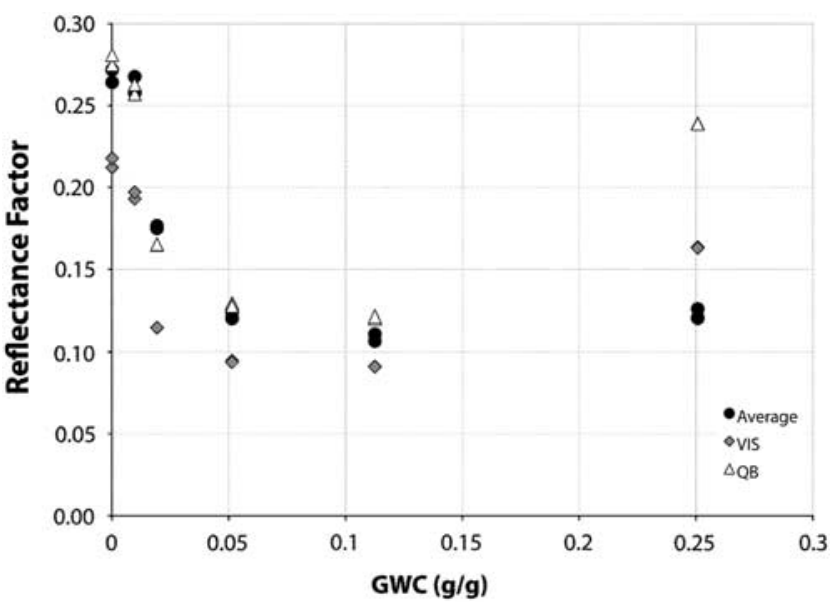

Fig. 4. Reflectance values for sample 018 as a function of gravimetric water content (GWC). Average $=$ mean values for the entire 350-2500 $\mathrm{nm}$ measurement range, VIS = average reflectance over visible wavelengths (400-700 nm), QB = average reflectance over QuickBird near-infrared observation wavelengths (760-850 nm).

\section{Methods}

\section{Sample collection}

Sediment samples were collected from the hill slopes surrounding Lake Hoare in Taylor Valley (Fig. 1) during summer 2010-11. Sediment from the upper $10 \mathrm{~cm}$ of the soil column was collected using clean plastic scoops and was placed in Whirl-Pak ${ }^{\circledR}$ bags. No weathering horizons or changes in texture or catena were observed in the sediment sampling pits, which is consistent with the minor role of chemical weathering in Dry Valleys soils (Ugolini \& Anderson 1973, Campbell et al. 1998), suggesting that these soils have largely homogenous compositions in the upper few centimetres. Accordingly, spectra of these bulk samples can be considered compositionally representative

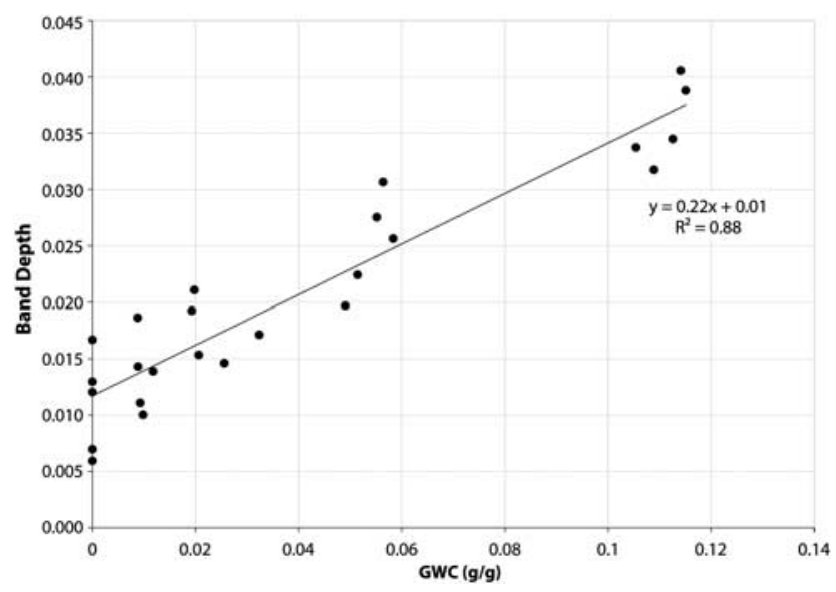

Fig. 5. Water absorption feature at $1.4 \mu \mathrm{m}$ band depths for all samples versus gravimetric water content (GWC). 

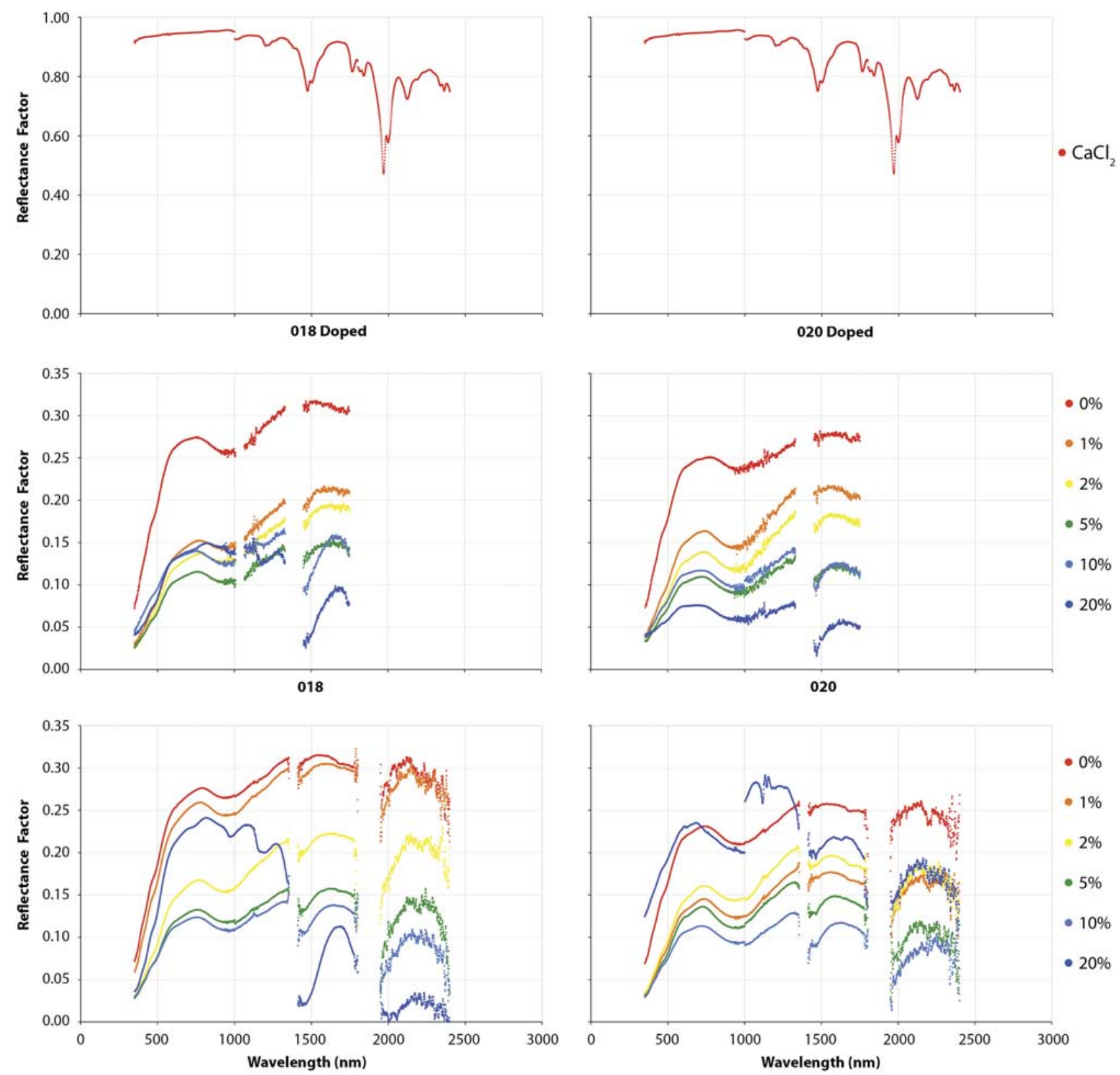

Fig. 6. (Top) Reflectance spectra of $\mathrm{CaCl}_{2}$ made under laboratory lighting conditions. Hydration of $\mathrm{CaCl}_{2}$ is apparent based on the presence of water absorption features near 1.4 and $1.9 \mu \mathrm{m}$. (Middle) Reflectance spectra of soil samples doped with $\mathrm{CaCl}_{2}$ in order to produce $\mathrm{CaCl}_{2}$ saturated brines. (Bottom) Reflectance spectra of soil samples hydrated only with deionized water. Note detector noise above $1.8 \mu \mathrm{m}$ resulted in truncation of the doped-sample spectra.

of the soil surface in the Dry Valleys. Sediments were kept frozen and brought to McMurdo Station, where they were oven dried at $105^{\circ} \mathrm{C}$ for 24 hours and allowed to cool. Sediments were then shipped to the USA for further analysis. Samples collected in this study came from a variety of hydrological environments, including wet water track soils (Barrett et al. 2009, Levy et al. 2011, Gooseff et al. 2013) (021 and 008; GWC at collection $=2.5 \%$ and $4.2 \%$, respectively), typically dry Dry Valleys hill slope soils (018 and 020; GWC at collection $=1.2 \%$ and $0.5 \%$, respectively), and damp wet patches (Lyons et al. 2005, Harris et al. 2007, Levy et al. 2011, 2012b) (039; GWC at collection $=1.3 \%$ ). Salt content of the soils in this study are $0.9 \%, 0.01 \%, 0.4 \%, 1.5 \%$ and $0.2 \%$ by mass for samples 021 , 020, 039, 008 and 018, respectively. All soils in this study are sandy calcic haplorthels dominated by medium-to-coarse sand and containing less than 5\% clays (Wilson 1979, Levy et al. 2012b, 2013). Typical clays in these soils include illite, smectite, chlorite, aragonite, calcite, sepiolite, talc and vermiculite (Levy et al. 2013). 


\section{Sample preparation}

Spectroscopic measurements described below were conducted on sediment samples that were rehydrated in the laboratory. Oven-dried samples were split into six c. $20 \mathrm{~g}$ subsamples that were placed into individual zipperseal sample bags (Fig. 3). Each sample was then rehydrated with a measured mass of deionized water in order to reach GWC targets of $0 \%, 1 \%, 2 \%, 5 \%, 10 \%$ and $20 \%$. Water plus sediment mixtures were then agitated in the sample bags for 1 minute to disperse the water and were allowed to equilibrate for 24 hours. In order to test whether extremely high salt contents, typical of Dry Valleys soils, would have an effect on water absorption features, replicate splits of two samples (018 and 020) were each doped with ovendried calcium chloride $\left(\mathrm{CaCl}_{2}\right)$, a common Dry Valleys salt (Wilson 1979, Barrett et al. 2009, Levy et al. 2012a, Toner et al. 2013), and mixed with water to form saturated $\mathrm{CaCl}_{2}$ brines. Like the non-doped samples, doped samples were allowed to equilibrate for 24 hours.

\section{Spectroscopic measurements}

Reflectance spectra of the experimentally wetted soils were collected using an Analytical Spectral Devices Full-Range Portable Field Spectrometer ${ }^{\mathrm{TM}}$ (ASD-FR). The ASD-FR measures spectral radiance across the wavelength range $0.35-2.5 \mu \mathrm{m}$ with spectral resolution of $0.003 \mu \mathrm{m}$ at $\lambda \approx 0.7 \mu \mathrm{m}$ and $0.01 \mu \mathrm{m}$ at $\lambda \approx 1.4 \mu \mathrm{m}$ and $2.1 \mu \mathrm{m}$. Values for its nominal noise equivalent change in radiance (ne $\Delta \mathrm{L})$ are $1.4 \times 10^{-9} \mathrm{~W} \mathrm{~cm}^{-2} \mathrm{~nm}^{-1} \mathrm{sr}^{-1}$ at $0.7 \mu \mathrm{m}$, $2.4 \times 10^{-9} \mathrm{~W} \mathrm{~cm}^{-2} \mathrm{~nm}^{-1} \mathrm{sr}^{-1}$ at $1.4 \mu \mathrm{m}$ and $8.8 \times 10^{-9} \mathrm{~W} \mathrm{~cm}^{-2}$ $\mathrm{nm}^{-1} \mathrm{sr}^{-1}$ at $2.1 \mu \mathrm{m}$. Spectral measurements were made using the ASD-FR equipped with an $8^{\circ}$ foreoptic. The foreoptic was held $c .15 \mathrm{~cm}$ above the sediment sample, producing a $c .2 \mathrm{~cm}$ diameter field of view. Soil samples were transferred from the mixing pouches into uncovered petri dishes for measurement. Spectra were measured under natural solar illumination within 1 hour of solar noon during July 2012 in Corvallis, OR $\left(44.6^{\circ} \mathrm{N}, 123.3^{\circ} \mathrm{W}\right)$. Reflectance factor (Schaepman-Strub et al. 2006) is reported as the ratio between the soil reflectance spectrum and a calibrated and levelled Spectralon ${ }^{\mathbb{B}}$ white reference target, and is reported as relative reflectance.

\section{Results}

The example reflectance spectrum of sample 018 is shown in Fig. 2, and the full collection of dry $(0 \%$ GWC) spectra along with the complete set of wetted reflectance spectra are shown in the supplementary material (found at http:// dx.doi.org/10.1017/S0954102013000977). The Dry Valleys soils measured in this experiment all have the same general spectral shape. They have generally higher reflectance at longer wavelengths in the ultraviolet-visible, typical of the tan/buff coloured soils in the Dry Valleys that contain some oxidized iron. The soils have a broad absorption near $1 \mu \mathrm{m}$, consistent with the presence of mafic sand grains in the sediments.

At visible $(0.4-0.7 \mu \mathrm{m})$ and panchromatic sensor $(0.45-0.9 \mu \mathrm{m})$ wavelengths, reflectance generally decreases with increasing soil moisture, but increases at high soil moisture contents (Fig. 4). Water absorption features at $1.4 \mu \mathrm{m}$ and $1.9 \mu \mathrm{m}$ are present in all wetted samples and increase in band depth with increasing GWC (Fig. 5, see discussion for details).

Finally, soil salinity has little effect on the signature of soil moisture content (Fig. 6). Maximum $1.4 \mu \mathrm{m}$ band depth varies only \pm 0.0025 over the full range of soil salinities measured, which would produce at most \pm 0.01 GWC; indicating that the calculated GWC offset resulting from saline fluids is smaller than the inherent model uncertainty.

\section{Discussion}

Here we discuss the spectroscopic properties of Dry Valleys soils as they relate to soil moisture and salinity. A more detailed description of the spectroscopic characteristics of Dry Valleys rocks, soils and sediments can be found in Wyatt et al. (2010) and Salvatore et al. (2013).

\section{Panchromatic albedo}

As noted by Langford et al. (unpublished), visible wavelength reflectance drops precipitously (more than $50 \%$ ) from $0-5 \%$ GWC, indicating that Dry Valleys soils darken efficiently with small additions of liquid water. However, beyond $10 \%$ GWC, reflectance increases in most samples owing to specular reflection from pooling bulk water in the samples near saturation (Lorenz 1966, Levy et al. 2012a). It should be noted that at visible wavelengths, relative reflectance for dry samples ranges between $c .0 .28$ and $c .0 .12$, and could be a consequence of several factors including soil colour, soil albedo, grain packing, self-shadowing, etc. For this reason, in order to quantify the amount of soil moisture in the samples, a different observable quantity is needed that can use reflectance differences to normalize between dry-wet and dry-dark sediments to produce a linear relationship between spectral properties and GWC.

\section{Water absorption feature band depth}

Water absorption features at $1.4 \mu \mathrm{m}$ and $1.9 \mu \mathrm{m}$ are present in all wetted samples. These absorption features are wavelengths of reduced reflectance by the wetted soils, relative to the Spectralon ${ }^{\circledR}$ target, resulting from absorption of infrared photons of these wavelengths by 
water molecules in the soil. For a given path length through the soil, more soil moisture results in greater chances for photon absorption, leading to decreased reflectance at these wavelengths (Clark \& Roush 1984). Some samples (e.g. 018) also contain a small $2.2 \mu \mathrm{m}$ absorption, consistent with the presence of hydroxyl ions in clays. Shifting of the $1.4 \mu \mathrm{m}$ absorption towards $1.450 \mu \mathrm{m}$ may be a result of the presence of chloride salts in the soils, notably $\mathrm{CaCl}_{2}$ (Crowley 1991).

Water absorption feature band depth was calculated by averaging two spectral regions outside of the water absorption feature (for the $1.4 \mu \mathrm{m}$ band, $1.319-1.349 \mu \mathrm{m}$ and $1.619-1.639 \mu \mathrm{m}$ were used; for the $1.9 \mu \mathrm{m}$ band, $1.623-1.647 \mu \mathrm{m}$ and $2.100-2.130 \mu \mathrm{m}$ were used). A flat continuum slope was fitted between the central value of the two averaging regions, defining the inferred shape of the spectrum had a water absorption feature not been present (Clark \& Roush 1984). Average reflectance on the deepest measureable part of the absorption feature was then measured (the actual absorption feature centre cannot be measured under natural illumination because atmospheric water vapour absorbs nearly all incoming photons at these wavelengths) (Fig. 2). Wavelength regions used in this study were $1.950-1.960 \mu \mathrm{m}$ for the $1.9 \mu \mathrm{m}$ feature and $1.415-1.435 \mu \mathrm{m}$ for the $1.4 \mu \mathrm{m}$ feature. Band depth was then calculated by subtracting the actual measured reflectance mean from the predicted reflectance value along the linear continuum slope (calculated at $1.955 \mu \mathrm{m}$ and $1.425 \mu \mathrm{m}$, respectively).

Water absorption feature band depth varies with GWC, as would be expected in relatively simple soils like those from the Dry Valleys (Abrams 2000, Lobell \& Asner 2002). The relationship between the $1.4 \mu \mathrm{m}$ band depth and GWC is shown in Fig. 5. Across the full range of GWC values, band depth varies linearly with GWC for wetted Dry Valleys soils, and can be approximated by the function, band depth $=0.22 \times \mathrm{GWC}$ (in $\mathrm{g} / \mathrm{g}$ ) +0.01 . The coefficient of determination value, $r^{2}$, for this model is 0.88 , and the result is statistically robust, with a linear regression $P$ value of $<0.01$. Data spread along this model is approximately $\pm 0.5 \%$ in relative reflectance, producing calculated GWC uncertainties of $\pm 2.5 \%$ GWC. For comparison, most dielectric soil moisture probes produce instrument measurement uncertainties of $\pm 1-2 \%$ GWC.

\section{Effect of salts}

Soil salinity has little effect on the signature of soil moisture content for Dry Valleys soils. Maximum $1.4 \mu \mathrm{m}$ band depth varies only \pm 0.0025 over the full range of soil salinities measured, which would produce at most $\pm 0.01 \mathrm{GWC}$, indicating that the calculated GWC offset resulting from saline fluids is smaller than the inherent model uncertainty. Water absorption features at 1.4 and
$1.9 \mu \mathrm{m}$ are apparent and readily measured even in the most saline sample, 008 (see supplementary material). Small shifts in the position of the absorption features are present in the $\mathrm{CaCl}_{2}$-doped samples, consistent with laboratory spectra of sulfate- and chloride-doped sediments (Entekhabi et al. 2008, Massé et al. 2012).

\section{Implications for remote sensing in the McMurdo Dry Valleys}

This pilot investigation of the reflectance properties of wetted Dry Valleys soils suggests that hyperspectral measurements of Antarctic soils may provide a lowimpact, contamination-free approach to measuring surface soil moisture properties across wide regions of the Dry Valleys and other ice sheet-free portions of Antarctica. These results are similar in accuracy to airborne measurements of soil moisture using reflectance spectra collected at temperate latitudes by Finn et al. (2011). Spectroscopic measurements of soil moisture content in this study produce GWC estimates with very similar uncertainty to contact measurements made via TDR or dielectric probes, suggesting that accuracy does not have to be significantly impacted in order to achieve wide spatial coverage. In addition, for soil moisture studies over small areas, contact-probe-based reflectance spectroscopy could be used to determine soil moisture conditions at the ground surface, providing an independent measurement technique to compare to traditional (TDR, mass-based) point measurements.

This investigation also highlights the need for hyperspectral imaging capabilities in the Dry Valleys if this laboratory tool is to be expanded to provide regional measurements of soil moisture content in support of biological or hydrogeological research (Stichbury et al. 2011, Gooseff et al. 2013). Existing multispectral satellite sensors, such as WV2 and QuickBird, have widespread spatial coverage over the Dry Valleys with high temporal return rates. However, our results show that these sensors do not have the necessary spectral resolution to discern the water absorption bands described in this study. In addition, these multispectral observatories avoid the vicinity of water absorption features in order to minimize atmospheric interference, making them even less able to determine surface soil moisture content quantitatively. Airborne imaging spectrometers, such as the Airborne Visible InfraRed Imaging Spectrometer (AVIRIS) (Green et al. 1998), have hyperspectral measurement capabilities similar to the spectroscopic range and resolution of the field spectrometer used in this study, and also have mature atmospheric correction algorithms. These spectrometers could be used to measure the water absorption features described here in order to determine the spatial and temporal distribution of surface soil moisture in Antarctic soils. 


\section{Conclusions}

The spectral reflectance factors of wetted Dry Valleys soils were measured under natural illumination conditions in order to determine whether spectroscopic tools can be used to quantitatively determine surface soil moisture content. Characteristic water absorption band depth, particularly at $1.4 \mu \mathrm{m}$, was found to vary linearly with GWC. The reflectance of dry soils at visible wavelengths was found to vary by over a factor of two, suggesting that visible wavelength measurements of soil moisture may be difficult to quantify, while these hyperspectral measurements of soil moisture have comparable accuracy to TDR soil moisture probes. These results indicate that future hyperspectral measurements of Dry Valleys soils could be used to quantitatively determine surface soil moisture content over wide areas using remote-sensing tools.

\section{Acknowledgements}

This work was supported by the NSF Office of Polar Programs Antarctic Earth Sciences division via award ANT-1343649 to JSL, AGF and W. Berry Lyons. This work benefitted from discussions with MCM-LTER team members (www.mcmlter.org) and from the comments of two anonymous reviewers.

\section{Supplemental material}

Two supplemental figures will be found at http://dx.doi. org/10.1017/S0954102013000977.

\section{References}

Abrams, M. 2000. The Advanced Spaceborne Thermal Emission and Reflection Radiometer (ASTER): data products for the high spatial resolution imager on NASA's Terra platform. International Journal of Remote Sensing, 21, 847-859.

Barrett, J.E., Gooseff, M.N. \& Takacs-Vesbach, C. 2009. Spatial variation in soil active-layer geochemistry across hydrologic margins in polar desert ecosystems. Hydrology and Earth System Sciences, 13, 2349-2358.

Bockheim, J.G., Campbell, I.B. \& McLeod, M. 2007. Permafrost distribution and active-layer depths in the McMurdo Dry Valleys, Antarctica. Permafrost and Periglacial Processes, 18, 217-227.

Campbell, I.B., Claridge, G.G.C., Campbell, D.I. \& Balks, M.R. 1998. The soil environment of the McMurdo Dry Valleys, Antarctica. Antarctic Research Series, 72, 297-322.

Clark, R.N. \& Roush, T.L. 1984. Reflectance spectroscopy: quantitative analysis techniques for remote sensing applications. Journal of Geophysical Research - Solid Earth, 89, 6329-6340.

Chinn, T.J. 1993. Physical hydrology of the Dry Valleys lakes. Antarctic Research Series, 59, 1-52.

Crowley, J.K. 1991. Visible and near-infrared (0.4-2.5 $\mu \mathrm{m})$ reflectance spectra of Playa evaporate minerals. Journal of Geophysical Research Solid Earth, 96, 16 231-16 240.
Entekhabi, D., Jackson, T.J., Nuoku, E., O’Neill, P. \& Entin, J. 2008. Soil moisture active/passive (SMAP) mission concept. SPIE Proceedings, 7085, 10.1117/12.795910.

Entekhabi, D., Nuoku, E.G. \& O’Neill, P.E. et al. 2010. The soil moisture active passive (SMAP) mission. Proceedings of the IEEE, 98 , 704-716.

Finn, M.P., Lewis, M., Bosch, D.D., Giraldo, M., Yamamoto, K., Sullivan, D.G. \& KinCAID, R. 2011. Remote sensing of soil moisture using airborne hyperspectral data. GIScience \& Remote Sensing, 48 , $522-540$

GoosefF, M.N., Barrett, J.E. \& Levy, J.S. 2013. Shallow groundwater systems in a polar desert, McMurdo Dry Valleys, Antarctica. Hydrogeology Journal, 21, 171-183.

Graser, E.A. \& van Bavel, C.H.M. 1982. The effect of soil moisture upon soil albedo. Agricultural Meteorology, 27, 17-26.

Green, R.O., Eastwood, M.L. \& Sarture, C.M. et al. 1998. Imaging spectroscopy and the airborne visible/infrared imaging spectrometer (AVIRIS). Remote Sensing of Environment, 65, 227-248.

Harris, K.J., Carey, A.E., Lyons, W.B., Welch, K.A. \& Fountain, A.G. 2007. Solute and isotope geochemistry of subsurface ice melt seeps in Taylor Valley, Antarctica. Geological Society of America Bulletin, 119, 548-555.

Hunt, H.W., Treonis, A.M., Wall, D.H. \& Virginia, R.A. 2007. A mathematical model for variation in water-retention curves among sandy soils. Antarctic Science, 19, 427-436.

Idso, S.B., Jackson, R.D., Reginato, R.J., Kimball, B.A. \& Nakayama, F.S. 1975. Dependence of bare soil albedo on soil water content. Journal of Applied Meteorology, 14, 109-113.

Ikard, S.J., Gooseff, M.N., Barrett, J.E. \& Takacs-Vesbach, C. 2009. Thermal characterisation of active layer across a soil moisture gradient in the McMurdo Dry Valleys, Antarctica. Permafrost and Periglacial Processes, 20, 27-39.

KenNedy, A.D. 1993. Water as a limiting factor in the Antarctic terrestrial environment: a biogeographical synthesis. Arctic and Alpine Research, 25, 308-315.

Levy, J.S., Fountain, A.G., Welch, K.A. \& Lyons, W.B. 2012 b. Hypersaline "wet patches" in Taylor Valley, Antarctica. Geophysical Research Letters, 39, 10.1029/2012GL050898.

Levy, J.S., Fountain, A.G., Gooseff, M.N., Welch, K.A. \& Lyons, W.B. 2011. Water tracks and permafrost in Taylor Valley, Antarctica: extensive and shallow groundwater connectivity in a cold desert ecosystem. Geological Society of America Bulletin, 123, 2295-2311.

Levy, J., Fountain, A., Gooseff, M., Barrett, J., Wall, D., Nielsen, U., Adams, B. \& Lyons, W.B. 2012a. Active layer processes in the McMurdo Dry Valleys, Antarctica: decadal trends and experimental responses to changes in soil moisture. Proceedings of the Tenth International Conference on Permafrost, 221-226.

Levy, J.S., Fountain, A.G., Gooseff, M.N., Barrett, J.E., Vantreese, R., Welch, K.A., Lyons, W.B., Nielsen, U.N. \& WALL, D.H. 2013. Water track modification of soil ecosystems in the Lake Hoare basin, Taylor Valley, Antarctica. Antarctic Science, 10.1017/S095410201300045X.

Lobell, D.B. \& Asner, G.P. 2002. Moisture effects on soil reflectance. Soil Science Society of America Journal, 66, 722-727.

Lorenz, D. 1966. The effect of the long-wave reflectivity of natural surfaces on surface temperature measurements using radiometers. Journal of Applied Meteorology, 5, 421-430.

Lyons, W.B., Welch, K.A., Carey, A.E., Doran, P.T., Wall, D.H., Virginia, R.A., Fountain, A.G., Csatho, B.M. \& Tremper, C.M. 2005. Groundwater seeps in Taylor Valley Antarctica: an example of a subsurface melt event. Annals of Glaciology, 40, 200-206.

Massé, M., Beck, P., Schmitt, B., Pommerol, A., Mcewen, A., Chevrier, V.F. \& Brissaud, O. 2012. Nature and origin of RSL: spectroscopy and detectability of liquid brines in the near-infrared. Lunar and Planetary Institute Science Conference Abstracts, 43, 1856. 
McKnight, D.M., Niyogi, D.K., Alger, A.S., Bomblies, A., Conovitz, P.A. \& TATE, C.M. 1999. Dry valley streams in Antarctica: ecosystems waiting for water. BioScience, 49, 985-995.

Salvatore, M.R., Mustard, J.F., Head, J.W., Marchant, D.R. \& Wyatt, M.B. 2013. Characterization of spectral and geochemical variability within the Ferrar Dolerite of the McMurdo Dry Valleys, Antarctica: weathering, alteration, and magmatic processes. Antarctic Science, 10.1017/S0954102013000254.

Schaepman-Strub, G., Schaepman, M.E., Painter, T.H., Dangel, S. \& Martonchik, J.V. 2006. Reflectance quantities in optical remote sensing - definitions and case studies. Remote Sensing of Environment, 103, 27-42.

Stichbury, G., Brabyn, L., Allan Green, T.G. \& Cary, C. 2011. Spatial modelling of wetness for the Antarctic Dry Valleys. Polar Research, 30, 10.3402/polar.v30i0.6330.
Toner, J.D., Sletten, R.S. \& Prentice, M.L. 2013. Soluble salt accumulations in Taylor Valley, Antarctica: implications for paleolakes and Ross Sea ice sheet dynamics. Journal of Geophysical Research - Earth Surface, 118, 198-215.

Ugolini, F.C. \& ANDERson, D.M. 1973. Ionic migration and weathering in frozen Antarctic soils. Soil Science, 115, 461-470.

VIRGINIA, R.A. \& WALL, D.H. 1999. How soils structure communities in the Antarctic dry valleys. BioScience, 49, 973-983.

WiLson, A.T. 1979. Geochemical problems of the Antarctic dry areas. Nature, 280, 205-208.

Wyatt, M.B., Head, J.W., Marchant, D.R., Harvey, R.P., Christensen, P.R., Salvatore, M.R. \& Horodyskyj, U.N. 2010. Orbital spectral mapping of surface compositions in the Antarctic Dry Valleys: regional distributions of secondary mineral-phases as climate indicators and implications for Mars. Lunar and Planetary Institute Science Conference Abstracts, 41, 2275. 